\title{
Distribution of iron supplements through the work place
}

\author{
Rohini De A Seneviratne', Dulitha Fernando', H. M. S. S. D. Herath ${ }^{2}$ \\ The Ceylon Journal of Medical Science 1999; 42:75-86
}

\begin{abstract}
Iron deficiency anaemia (IDA) is a recognized public health problem in Sri Lanka. IDA in working women has been shown to affect their work performance and work productivity. This study was carried out to assess the feasibility of using the workplace for iron supplementation through assessment of opinion of management by holding discussions; attitudes and opinion of women workers using focus group discussions (FGD); and existing health and welfare facilities in the industries in the Free Trade Zones (Investment Promotion Zones) and in the Colombo city, by survey.
\end{abstract}

Rapid assessment procedures (RAP) were used The discussion held with the private sector industries showed that the attitude of the management to on-site iron supplementation was positive. Several industries had existing health and welfare programmes and they could be used with minimal increase of the cost. A concern of the management was that on site supplementation should not cause side effects, which would affect production.

The existing welfare packages included: provision of free $(63 \%)$ and subsidized $(16.3 \%)$ meals; iron (8\%) and vitamin (8\%) supplements at work; and worm treatment $(7 \%)$. Overall, $17.7 \%$ of women workers surveyed were observed to benefit from iron supplementation.

The FGDs showed the level of knowledge on IDA and its prevention to be unsatisfactory among women workers. There was a need to develop effective IEC material for the workers and the management. Control of IDA in the private sector workplace could be a useful and effective option that may be worthwhile pursuing.

\section{Introduction}

The extent of iron deficiency anaemia (IDA) among working women in Sri Lanka, has not been studied systematically, except among the women plantation workers. A survey conducted in 1990, among female workers in the Investment Promotion Zone (IPZ) at Katunayake revealed that $65 \%$ of them were anaemic on clinical examination and worm infestations were present among $15 \%$ (1). A study carried out in a factory in China indicated that IDA affects work performance and productivity and anaemic women have been reported to produce, on the average, $5.7 \%$ less (2). A study among women workers in the plantation sector in Sri Lanka showed an increase in work output with improvement in their haemoglobin status (3).

The workplace, specially where women workers predominate, could be a suitable place to implement an iron supplement programme. The workers constitute a population of similar background, education and aspirations and therefore implementing and monitoring a supplementation programme should not be difficult. Further, existing facilities for delivery of health and welfare services could be used. On site supplementation where the recipient would take a tablet under direct observation would eliminate problems of poor compliance.

The cost of such supplementation is less that ten cents (Sri Lanka currency) per tablet of ferrous

1. Departmenit of Community Medicine, Faculty of Medicine, Kynsey Road,Colombo 8.

2. Public Health Consultant, Ministry of Health, Sri Lanka. 
sulphate. Managers of industries need to be convinced of the advantages and benefits from iron supplementation to ensure acceptance and participation.

For such reasons ${ }^{\prime}$ it was decided to study the feasibility of using the workplace to address the problem of IDA among working women.

The objectives of the study were to:

i. Obtain the views and opinions of the management at all levels on implementing a programme of iron supplementation among the female workforce.

ii. Assess the attitude and opinion of women workers on such a programme.

iii. Study the different approaches available for iron supplementation within the on-going welfare programmes.

\section{Methods}

1. Meetings and discussions were held with management personnel from:

1.1. The Board of Investment (BOI) responsible for the planning, development of infrastructure and promoting the setting up of industries by foreign investors in the IPZ.

1.2. Employer's Federation of Ceylon (EFC), an organization representing nearly 500 industries and other workplaces.

1.3. Small and medium scale industries from the private sector in the city of Colombo.

2. Focus group discussions (FGDs) were conducted with representatives from women workers.

3. A survey was carried out to study the existing health and welfare facilities in the workplace, using a questionnaire. The self-administered questionnaire was designed to collect information on: socio-demographic data of the workforce; provision of nutritional supplements and free/subsidized meals; and facilities available for treatment of injuries and illnesses. The questionnaire was mailed to the managers of the industries comprising members of the EFC. A covering letter, explaining the objectives of the study and requesting their assistance in obtaining data, and a stamped envelope addressed to the principal investigator (PI) were also enclosed. Unfortunately, a strike by the Postal Department, which lasted a few weeks delayed delivery of letters, so that the response rate from the non BOI, EFC members was only $60 \%$. Questionnaires were also distributed to small and medium-scale industries in the city of Colombo through the area Public Health Inspectors. These officers were responsible for occupational and environmental health related issues in their areas.

Due to time and resource constraints, rapid assessment procedures (RAPs) were used (4).

\section{Results}

1. Discussions with the management:

Permission to implement this component of the study was requested from the Director of Industrial Relations Department (IRD) of the IPZs, through the Senior Zone Managers. The IRD of the respective IPZ was responsible for the selection of industries included in the study. This may have introduced a possible bias.

\subsection{Biyagama IPZ}

Four establishments, one each from among the industries producing ceramicware, processed tobacco, microchips and garments were included in the study. Representatives from these industries as well as the Director, IRD participated in the meeting.

\subsubsection{Ceramic industry}

This industry employed about 2000 workers, of whom $80 \%$ were female. The industry provided iron and vitamin supplements, on site, but the 
program was stopped about two years ago due to poor compliance among workers.

The reasons listed for poor compliance were:

i. A majority of workers were from rural areas and had negative attitudes towards taking tablets, preferring home remedies. Many would prefer to take leave and go home, if they feel unwell.

ii Vague symptoms such as giddiness, faintness and problems related to menstruation were related to the intake of tablets.

The main reason for these observations was inadequate knowledge and lack of an effective educational program preceding the distribution of iron. Even though the IRD organized health educational activities, only a limited number attended those sessions. As the overriding concern of the management and workers. was uninterrupted production, only ten or less workers were sent from each industry to attend the educational programmes. At the time of the visit, iron tablets were distributed only to those requesting for such supplements and were provided at the Health Centre. The supplement had to be taken "on site".

Introducing an iron supplementation programme was considered feasible, provided educational activities preceded such programmes. All efforts should be made to minimize, side effects of iron. "Giving a tablet and losing a worker must be avoided at all costs".

\subsubsection{Tobacco processing industry}

A total of 1800 workers, comprising $85 \%$ females are employed in processing tobacco for export. This industry has a Medical Centre with a full time Medical Officer and five nurses employed on a shift basis.

A program for providing iron and vitamin supplements was being implemented on the recommendation made by the Medical Officer, who noticed that several workers presented with vague complaint which he attributed to IDA. The tablets were distributed by the nurses and the supervisors. The workers were expected to take them 'on site'. This practice has been discontinued as the workers were not pleased with this arrangement. At the time of the study the workers have to request for the tablets from the Health Center. They are expected to take them then and there. There were more requests for vitamins than for iron. The industry intends to continue this program and would consider making appropriate modifications, if required.

\subsubsection{Electronic industry}

In this Factory, iron and other supplements are available at the Health Centre. There is no organized supplementation programme. The employees here, who have, passed GCE Ordinary Level Examination and above, are more educated compared to those in other industries. The main concern of the management was that introduction of a supplementation programme should not have a negative effect on production, due to side effects.

The management is ready to consider the introduction of supplementation provided it is preceded by an educational programme.

\subsubsection{Garment industry}

A total of 920 workers, approximately $90 \%$ of whom were female, were employed in this factory. A majority of them were from rural areas and have had more than 10 years of schooling.

Following the establishment of the factory, the management provided iron tablets to all workers. The person in charge of the sick room and the supervisors distributed them to the workers while at work, usually at about 10 a.m. This programme was started because of complaints of faintness, weakness and other symptoms. Workers were educated on the need for such supplementation and compliance has been satisfactory. After about 18 months, the management considered that providing a breakfast was a better alternative. Accordingly, about 3 years ago, 
the employees were provided with breakfast and the supplementation program was discontinued. The management does not see the need to give supplements in addition to the breakfast. However, if considered beneficial, supplementation could be re-introduced as the extra cost is not high.

\subsection{Industries in the Katunayake IPZ}

A group discussion was held at the Zone Office of the IRD of the BOI at Katunayaka, which was attended by representatives from 11 garment industries and one manufacturing industry.

Nine out of the 12 industries (75\%) supplied iron and vitamins $A \& D, B$, and $C$ as capsules, tablets or syrups. All supplements were paid for by the industry. The industries obtained the supplies from the Health Centre at the IPZ.

All supplements were distributed through the Health Centre in each factory via the nurse or the person in charge. Most industries made iron tablets available on demand, on a daily basis. Iron containing syrups or a week's supply of tablets were given to be taken home. In general, the number using such facilities ranged from $8-10$ per day to $20-30$ per day. One industry supplied iron to workers during the period preceding their menstruation. Tablets had to be swallowed at the Health Centre. The response has been good with $200-300$ persons responding. According to the nurses, absenteeism has declined and so have the complaints about giddiness, abdominal pain etc.

There was no established mechanism for informing the workers about the availability of such facilites. There was no formal educational programme on prevention of IDA, usefulness of iron supplementation etc.

\section{Role of management}

In general, the management took a positive attitude towards implementing these programmes. Ten out of 12 industries provided all work- ers, a free breakfast or another meal, depending on the shifts. One industry paid a meal allowance.

\section{Future activities}

As numbers are large, it will not be possible for the Health Centre to distribute supplements, hence the following possibilities were discussed.

i. Give one tablet at the time of 'Punching' their cards, at entry to the factory.

ii. Giving a tablet with the meal provided by the factory.

iii. Making the tablets available at the canteen and the distribution to be done by the health staff.

iv. Distribution through supervisors

Any procedure used for distribution should not interfere with production related activities.

An important prerequisite for supplementation is the education of workers. Suggested methods were: posters specially designed for working women, pamphlets using pictures, cartoons etc. Short lecture /discussions during the lunch break, playing prepared cassettes over the public address system which were found in most work places.

\section{Conclusions from discussion}

1. Provision of iron supplements at work place is acceptable to the management

2. Decisions regarding the distribution can be taken by the management with approval from the Board of Management

3. Cost of supplementation is acceptable. Additional cost is unlikely to inflate the cost of the present welfare package

4. Supplementation programmes to be preceded by effective educational programmes, for management and workers

5. Production is the main concern of the management 


\section{Focus group discussions with women workers}

Focus group discussions were held with groups of women workers, to get an in-depth knowledge on their beliefs, attitudes and perceptions about iron, iron deficiency and need for iron supplementation in the workplace.

Three FGDs were held with women from 3 different types of work organizations. They were selected from a Garment Industry in the BIPZ, from a large scale confectionery production enterprise and a medium scale garment industry outside the IPZ projects. The participants were selected by the management following the guidelines given by the research team. All were women between 18 - 25 years and were regarded as being of similar socioeconomic background and educational level.

Summary of the responses are given below.

\section{Foods rich in iron}

All acknowledged that green leaves is the best source of iron. Many did not think of meat and fish, as good sources and some mentioned marmite as a good source because of its colour.

\section{Iron supplements}

They knew that there were different types of supplements. All knew about the colour and taste of iron tablets. Most had not taken any tablets. They had no negative attitudes towards tablets. A majority identified "iron" and "vitamins" as one and the same thing.

\section{Health effects of deficiency}

Most of them identified leg pains, reduced strength, skin changes and decaying teeth as being due to iron deficiency. None mentioned anaemia or a word similar to anaemia. Anaemia to them meant 'reduced strength'.
Overdose of iron

Two women in the Colombo Garment factory had a fear of getting addicted to iron. Others had no such fears.

\section{Iron requirements}

No one identified a need for iron during lactation. Most were aware of a greater need during pregnancy and in special situations. Most considered that normal people do not need iron. Those who should take iron were identified as pregnant women.

Among others who needed iron were growing children to get energy for development, heavy manual workers, farmers, labourers to recover "waste" and menstruating women for whom no reasons were given.

Even groups which had married women did not appreciate the need for iron during lactation.

\section{Other observations}

Many of them said tea destroyed or burnt vitamins. They believed that healthy mothers will have healthy babies and iron was thought to be good for mothers and for the development of the baby.

All appreciated the idea of receiving iron at the work place. All strongly felt that iron should be taken after medical examination and on the advice of a doctor.

\section{Survey of industries}

: This component of the study was carried out in 186 industries, 80 in the Katunayake IPZ (KIPZ $43 \%), 51$ in the Biyagama IPZ (BIPZ - 27.4\%) and 55 from the Colombo city and EFC members (Others - 29.6\%). The response rates to the questionnaire were $86 \%$ from KIPZ, $100 \%$ from BIPZ and $50 \%$ from others. 
Table 1 shows the distribution of industries in the sectors surveyed. Nearly $50 \%$ of those in the KIPZ were garment industries and $28 \%$ belonged to the category "Other", while the opposite was observed at BIPZ. One third of the industries outside the IPZs were manufacturing rubber, plastics, ceramic goods, glassware and other consumer goods and another one third were garment/textile industries. Of all workplaces surveyed one third were garment/textile industries.

There were 127,726 workers employed in all the industries surveyed, ranging from 3 to 9998 and a mean of 687 persons per workplace. A majority $(70 \%)$ of the workers were female (Table 2 ). In the five estates surveyed, there were both factory workers and field workers (tea pluckers, rubber tappers). Office workers accounted for 6621 , of whom $48 \%$ were female.
The distribution of female workers ranged from 0 - 5994, with a mean number of 413 per workplace. Thirty eight percent $(38 \%)$ of the industries employed less than 50 female workers (Table 3). Of these $60 \%$ were from the EFC and Colombo city (outside the IPZ) A further $28 \%$ had 100 to 499 workers. Of the 20 industries with over 1000 workers, $75 \%$ were in the KIPZ.

The female workers were employed in diverse fields (Table 4). Thirty three percent of the female workers were employed in garment industries. Fifty seven percent of industries employing 10001999 and $83.3 \%$ employing 2000 or more workers were garment industries. Women were also employed in manufacturing rubber/plasticgoods, manufacturing electronic/electrical appliances and on tea and rubber estates.

\section{Table 1}

Distribution of industries by type and location

\begin{tabular}{lrrrrrrrrrr}
\hline & \multicolumn{7}{c}{ Location } \\
\hline Type & \multicolumn{2}{c}{ KIPZ } & \multicolumn{2}{c}{ BIPZ } & \multicolumn{2}{c}{ Other } & \multicolumn{2}{c}{ Total } \\
of Industry & No & $\%$ & No. & $\%$ & No. & $\%$ & No. & $\%$ \\
\hline Garment/Textile & 38 & 47.5 & 11 & 21.6 & 12 & 21.8 & 61 & 32.8 \\
Electronic/electric & 13 & 16.3 & 3 & 5.9 & 12 & 21.8 & 28 & 15.0 \\
Rubber/plastic & 5 & 6.2 & 8 & 15.7 & 19 & 34.5 & 32 & 17.2 \\
Diamond/jewellary & 2 & 2.5 & - & - & - & - & 2 & 1.0 \\
Food & - & - & 2 & 3.9 & 7 & 12.7 & 9 & 4.8 \\
Estates & - & - & - & - & 5 & 9.1 & 5 & 2.7 \\
Other & 22 & 27.5 & 27 & 52.9 & - & - & 49 & 26.4 \\
\hline All & 80 & 100 & 51 & 100 & 55 & 99.9 & 186 & 99.9 \\
\hline
\end{tabular}

$\mathrm{KIPZ}=$ Katunayake Investment Promotion Zone

$\mathrm{BIPZ}=$ Biyagama Investment Promotion Zone 
Table 2

Distribution of the work force by gender and type of work

\begin{tabular}{|c|c|c|c|c|c|c|}
\hline \multirow{3}{*}{$\begin{array}{l}\text { Type of } \\
\text { work }\end{array}$} & \multicolumn{6}{|c|}{ Gender } \\
\hline & \multicolumn{2}{|c|}{ Male } & \multicolumn{2}{|c|}{ Female } & \multicolumn{2}{|c|}{ Total } \\
\hline & No. & $\%$ & No. & $\%$ & No. & $\%$ \\
\hline Factory & 22,933 & 22.9 & 76,956 & 77.1 & 99889 & 78.2 \\
\hline Estate & 8912 & 51.4 & 8435 & 48.6 & 17347 & 13.6 \\
\hline Office & 3452 & 52.1 & 3169 & 47.8 & 6621 & 5.2 \\
\hline Other & 2580 & 66.7 & 1289 & 33.2 & 3869 & 3.0 \\
\hline All & 37,877 & 29.6 & 89,849 & 70.4 & 127,726 & 100 \\
\hline
\end{tabular}

The numbers relate to the total population studied

Table 3

Distribution of industries by number of female workers and location

\begin{tabular}{|c|c|c|c|c|c|c|c|c|}
\hline \multirow{3}{*}{$\begin{array}{c}\text { Female } \\
\text { workers }\end{array}$} & \multicolumn{8}{|c|}{ Location } \\
\hline & \multicolumn{2}{|c|}{ KIPZ } & \multicolumn{2}{|c|}{ BIPZ } & \multicolumn{2}{|c|}{ Other } & \multicolumn{2}{|c|}{ Total } \\
\hline & No. & $\%$ & No. & $\%$ & No. & $\%$ & No. & $\%$ \\
\hline $0-49$ & 16 & 20.0 & 20 & 39.3 & 32 & 59.2 & 70 & 37.8 \\
\hline $50-99$ & 2 & 2.5 & 5 & 9.8 & 8 & 14.8 & 15 & 8.1 \\
\hline $100-499$ & 27 & 33.6 & 14 & 27.5 & 11 & 20.3 & 52 & 28.1 \\
\hline $500-999$ & 20 & 25.0 & 9 & 17.6 & 1 & 1.9 & 28 & 15.1 \\
\hline $1000-1999$ & 10 & 12.5 & 1 & 2.0 & 1 & 1.9 & 13 & 7.0 \\
\hline$>=\mathbf{2 0 0 0}$ & 5 & 6.3 & 2 & 3.8 & 1 & 1.9 & 7 & 3.8 \\
\hline Total & 80 & 99.9 & 51 & 100 & $54^{*}$ & 100 & 185 & 99.9 \\
\hline
\end{tabular}

* Information not available for one industry (c.f. Table 1)

KIPZ = Katunayake Investment Promotion Zone

BIPZ = Biyagama Investment Promotion Zone 
Table 4

Distribution of female workers by number of workers and type of industry

\begin{tabular}{|c|c|c|c|c|c|c|c|c|c|c|c|c|}
\hline \multirow{3}{*}{$\begin{array}{l}\text { No. of } \\
\text { workers }\end{array}$} & \multicolumn{12}{|c|}{ Type of industry } \\
\hline & \multicolumn{2}{|c|}{ Garment } & \multicolumn{2}{|c|}{ Electronic } & \multicolumn{2}{|c|}{$\begin{array}{l}\text { Rubber / } \\
\text { plastic etc. }\end{array}$} & \multicolumn{2}{|c|}{ Food } & \multicolumn{2}{|c|}{ Estates } & \multicolumn{2}{|c|}{ Other } \\
\hline & No. & $\%$ & No. & $\%$ & No. & $\%$ & No. & $\%$ & No. & $\%$ & No. & $\%$ \\
\hline $0-49(n=70)$ & 5 & 7.2 & 22 & 31.9 & 18 & 26.1 & 7 & 10.1 & 2 & 2.9 & 16 & 21.7 \\
\hline $50-99(n=15)$ & 6 & 40 & 2 & 13.3 & 4 & 26.6 & 0 & 0 & 0 & 0 & 3 & 20 \\
\hline $100-499(n-52)$ & 27 & 54 & 1 & 2 & 6 & 12 & 1 & 2 & 1 & 2 & 16 & 30 \\
\hline $500-999(n=28)$ & 10 & 37 & 2 & 7.4 & 4 & 14.8 & 0 & 0 & 1 & 3.7 & 11 & 37 \\
\hline $1000-1999(n=14)$ & 8 & 57.1 & 1 & 7.1 & 2 & 14.2 & 1 & 7.1 & 0 & 0 & 1 & 14.2 \\
\hline$>=2000(n=7)$ & 5 & 83.3 & 0 & 0 & 0 & 0 & 0 & 0 & 1 & 16.7 & 1 & 0 \\
\hline
\end{tabular}

* Information not avaiable for one industry (c.f. Table 1)

$\mathrm{n}=$ number of industries

\section{Availability of healthcare facilities}

The question requesting information on availability of health facilities at the workplace received responses from 175 (94\%) industries. Forty six (25\%) stated that facilities to obtain treatment for illnesses was available while a slightly higher percentage (28.6\%) reported the availability of facilities for treatment of injuries (Table 5).

A Medical Centre with a qualified medical officer was available in each of the IPZs. Each industry in the IPZ contributed Rs. 12/= per worker per year to this organization which provided basic treatment and investigation facilities. Facilities for provision of dental care and on-call emergency services, including an ambulance were available through this source.

In the non IPZ industries, $80 \%$ indicated that they had treatment facilities. This statement has to be interpreted with caution, as it is possible that even the availability of analgesics could have been interpreted as having treatment facilities. The percentage of industries in the non IPZ that pro- vided facilities for treatment of injuries was high $(84 \%)$. In the IPZ areas, the corresponding percentages were $1.3 \%$ in the KIPZ and $7.3 \%$ in the BIPZ. However, this service was provided by the Health Centre in the Zone.

\section{Availability of welfare facilities}

A first aid box was available in more than $90 \%$ of all industries. According to the Factories Ordinance such a facility was mandatory. In the KIPZ, $98 \%$ of the factories has a person who was responsible for maintenance of first aid facilities, the comparable proportion in the BIPZ being $70 \%$. Persons trained in first aid were available in $88 \%$ of the KIPZ factories and only in $66 \%$ of the factories in other two locations. The number of persons trained in first aid ranged from 0 to 25 .

An ambulance was available in $6 \%$ of the workplaces, with some other vehicle being available in $95 \%$ of the factories. In all non BOI industries and $22 \%$ of KIPZ and $7.3 \%$ of BIPZ industries, the services of a Medical Officer was made avail- 
able by formal arrangement with a General Practitioner from the area. In $75 \%$ of the work places surveyed, there was a Health Centre, their percentage being relatively low $(40 \%)$ in the non $\mathrm{BOI}$ industries.

Health Education Programmes conducted in $23 \%$ of the industries mainly focused on areas of industrial safety, oral health, STD/AIDS etc. The non IPZ factories had more of such inputs than those in the IPZ.

The availability of nutrient supplementation and worm treatment is shown in Table 6. Eight percent of industries reported having iron supple- ment at work place. Vitamin supplements were available in $9 \%$ and worm treatment in $7.4 \%$.

The number of women workers who could have benefited from this is shown in Table 7. Overall, $17 \%$ of the women were potential beneficiaries of iron and vitamin supplementation and by worm treatment.

Free meals were supplied to workers in two thirds of the factories surveyed, breakfast being the meal commonly supplied. Four factories gave a meal allowance instead. Free tea was given in $91 \%$ of the factories. All industries that provided free meals also provide iron supplements.

Table 5

Availability of health care facilities in the factories by location

\begin{tabular}{|c|c|c|c|c|c|c|c|c|}
\hline \multirow{3}{*}{ Facility } & \multicolumn{8}{|c|}{$\%$ of factories with the facility } \\
\hline & \multicolumn{2}{|c|}{ KIPZ } & \multicolumn{2}{|c|}{ BIPZ } & \multicolumn{2}{|c|}{ Other } & \multicolumn{2}{|c|}{ Total } \\
\hline & $\mathbf{N}$ & $\%$ & $\mathbf{N}$ & $\%$ & $\mathbf{N}$ & $\%$ & $\mathbf{N}$ & $\%$ \\
\hline First aid box & 79 & 98.8 & 49 & 93.9 & 55 & 90.9 & 184 & 95.1 \\
\hline $\begin{array}{l}\text { Person for maintenance } \\
\text { of first aid box }\end{array}$ & 79 & 97.5 & 46 & 69.6 & 51 & 92.2 & 176 & 88.6 \\
\hline $\begin{array}{l}\text { Person trained } \\
\text { in first aid }\end{array}$ & 80 & 88 & 49 & 65.3 & 55 & 65.5 & 181 & 73.9 \\
\hline Ambulance & 80 & 1.3 & 50 & 0 & 55 & 18.2 & 85 & 5.9 \\
\hline $\begin{array}{l}\text { Other vehicle to } \\
\text { transport of patients }\end{array}$ & 80 & 98.8 & 50 & 100 & 55 & 85.5 & 185 & 95.7 \\
\hline Doctor - Full time & 80 & 0 & 50 & 0 & 55 & 10.9 & 184 & 3.3 \\
\hline Doctor - Part time & 80 & 21.3 & 49 & 0 & 55 & 27.3 & 184 & 17.4 \\
\hline Nurse - Full time & 80 & 62.5 & 49 & 22.4 & 55 & 21.8 & 184 & 39.7 \\
\hline Nurse - Part time & 80 & 0 & 49 & 0 & 55 & 5.5 & 184 & 1.6 \\
\hline $\begin{array}{l}\text { Formal arrangement } \\
\text { with GP }\end{array}$ & 80 & 1.3 & 50 & 0 & 55 & 69.1 & 185 & 21.1 \\
\hline Health Centre & 80 & 90 & 49 & 85.7 & 55 & 40 & 184 & 73.9 \\
\hline $\begin{array}{l}\text { Health education } \\
\text { programme in place }\end{array}$ & 79 & 21.5 & 41 & 7.3 & 54 & 37 & 174 & 23 \\
\hline
\end{tabular}

$\mathrm{GP}=$ General practitioner.

$\mathrm{n}=$ number of factories

Vol. 42 No.2, December 1999 
Table 6

Availability of nutrient supplements and worm treatment in the factories by location

\begin{tabular}{|c|c|c|c|c|c|c|c|c|}
\hline \multirow[t]{3}{*}{ Facility } & \multicolumn{8}{|c|}{$\%$ of factories with the facility } \\
\hline & \multicolumn{2}{|c|}{ KIPZ } & \multicolumn{2}{|c|}{ BIPZ } & \multicolumn{2}{|c|}{ Others } & \multicolumn{2}{|c|}{ Total } \\
\hline & $\mathbf{N}$ & $\%$ & $\mathbf{N}$ & $\%$ & $\mathbf{N}$ & $\%$ & $\mathbf{N}$ & $\%$ \\
\hline Iron supplements & 79 & 8.9 & 41 & 2.4 & 55 & 10.9 & 175 & 8 \\
\hline Vitamin supplements & 79 & 11.4 & 41 & 7.3 & 55 & 7.3 & 175 & 9 \\
\hline Worm treatment & 79 & 2.5 & 42 & 7.2 & 55 & 14.5 & 176 & 7.4 \\
\hline
\end{tabular}

KIPZ = Katunayake Investment Promotion Zone BIPZ = Biyagama Investment Promotion Zone $\mathrm{N}=$ number of factories

Table 7

\% Availability of supplements and worm treatment for female factory workers by location of industry

\begin{tabular}{|c|c|c|c|c|c|c|c|c|}
\hline \multirow{3}{*}{ Available } & \multicolumn{6}{|c|}{ Location } & \multirow{2}{*}{\multicolumn{2}{|c|}{$\begin{array}{c}\text { Total } \\
(76775)\end{array}$}} \\
\hline & \multicolumn{2}{|c|}{$\underset{(n=47690)}{\mathrm{KIPZ}}$} & \multicolumn{2}{|c|}{$\begin{array}{c}\text { BIPZ } \\
(n=17684)\end{array}$} & \multicolumn{2}{|c|}{$\begin{array}{c}\text { Other } \\
(n=11401)\end{array}$} & & \\
\hline & $\mathbf{N}$ & $\%$ & $\mathbf{N}$. & $\%$ & $\mathbf{N}$ & $\%$ & $\mathbf{N}$ & $\%$ \\
\hline 1. Vitamins & 9227 & 19.3 & 2394 & 13.5 & 1703 & 14.9 & 13324 & 17.4 \\
\hline 2. Iron & 8270 & 17.3 & 1601 & 9.1 & 2403 & 21.1 & 13324 & 17.3 \\
\hline 3. Worm treatment & 2409 & 5.1 & 2018 & 11.3 & 9096 & 79.8 & 13527 & 17.5 \\
\hline
\end{tabular}

$\mathrm{KIPZ}=$ Katunayake Investment Promotion Zone $\mathrm{BIPZ}=$ Biyagama Investment Promotion Zone $N=$ Number of workers for whom supplements are available $\mathrm{n}=$ Total number of workers in investment Promotion Zone 


\section{Discussion}

This study revealed that most industries have an existing system and mechanism for health and welfare activities. These appear to be better organised in the Industrial Promotion Zones. The welfare package included facilities ranging from free $(63 \%)$ / / subsidized $(16.3 \%)$ meals to nutrient supplementation (iron $8 \%$, multi-vitamin $9 \%$ ) and worm treatment (7\%). Overall, $17 \%$ of women were observed to benefit from iron supplementation programmes.

The detailed discussions with the management and those responsible for the health centres revealed that the actual numbers availing themselves of the facilities of the iron supplementation programme was very low. Absence of a formal mechanism to create an awareness of the existence of the facilities, poor knowledge of the benefits of iron supplementation, and the attitudes of the women themselves to the supplementation programme were the likely reasons.

However, FGDs revealed that the workers themselves on the whole had a positive attitude towards the idea of iron supplementation in the workplace. They identified iron as something that gave the necessary strength to do the work. They held the view that iron tablets were to be taken on the recommendation of a doctor. If recommended so, and given at the workplace they would be happy to take iron tablets. Some of the female workers especially those with a rural background generally seem to be averse to the idea of taking 'tablets'. Further research would be needed to identify the underlying reasons for this.

In general the level of knowledge on issues related to anaemia-control, specifically in relation to work, seems to be unsatisfactory. There is a need to develop effective IEC material on anaemia-control, targeting women workers.

In this study FGDs was found to be very useful in obtaining in depth information which are not reveled in usual questionnaire surveys (5).
A very important concern expressed by the management was that such supplements should not cause side effects thereby interfering with production. Thus, proper education of both the management and the workers is a key pre-requisite to a supplementation programme.

In view of the fact that only a select group of personnel from the management were available for discussions in this study, it will be necessary to hold advocacy meetings in anaemia-control with the relevant authorities/organizations in order to obtain suggestions/directives if such programs are to be implemented through the work places, on a large scale.

\section{Acknowledgements}

We wish to thank Dr. W. R. de Alwis Deputy Commissioner of Labour, Director General of the Employer's Federation of Ceylon, Director Environment Division of Board of Investment, Colombo and the Directors of the Industrial Relations Divisions of Industrial Processing Zones at Katunayaka and Biyagama for the co-operation extended to us.

Funding for the study granted by OMNI, USA is acknowledged.

\section{References}

1. De A Seneviratne R, De Alwis W R, Jayamanne D, Gunaratne D D. Report of Canadian International Development Agency project, 'To recognize and evaluate factors that adversely affect the health status of female workers in the FTZ in Katunayaka'. Colombo; Department of Community Medicine, Faculty of Medicine, University of Colombo, 1990.

2. Scholz B D, Gross R, Schultink W, Sastroamdjojo $S$. Anaemia is associated with reduced productivity of women workers even in less physically strenuous tasks. British Journal of Nutrition 1997; 77 : 45-57. 
3. Atukorala T N and De Silva L D R. Report on, 'Evaluation of the intervention measures available against anaemia in pregnancy among plantation women of Sri Lanka'. Colombo: Department of Biochemistry, Faculty of Medicine. University of Colombo, 1991.

4. Martha A. Epidemiological and statistical methods for Rapid Health Assessment. World Health Statistics Quarterly. 1991; 44: 94-97.

5. Khan M E.The use of focus groups in social and behavioural research: some methodological issues. World Health Statistics Quarterly. 1991; 44: 145-149. 